\title{
periferio
}

\section{POR UMA EDUCAÇÃO FÍSICA CRÍTICA NO ENSINO MÉDIO EM MACAPÁ}

\author{
Mayê Guedes Dantas 1 \\ Centro de Ensino Superior do Amapá - CEAP \\ Fátima Lúcia Carrera Guedes Dantas² \\ Universidade Federal do Amapá - UNIFAP \\ Mesaque da Silva Correia ${ }^{3}$ \\ Instituto Federal de Educação do Amapá - IFAP
}

\section{Resumo}

Este trabalho é assentado no resultado de uma pesquisa que visou responder o porquê da desmotivação dos alunos nas aulas de Educação Física do Ensino Médio em Macapá. O resultado demonstra que o problema se fundamenta em questões históricas e ligadas ao sistema educacional dentro de um contexto maior: a sociedade capitalista moderna com todo seu aparato sistêmico. Historicamente, a Educação Física foi baseada numa concepção militarista espartana de adestramento de seres imperfeitos e, tal legado influenciou os rumos da educação nessa área. Atualmente, a instituição do esporte, via influência midiática, tenta sobrepor-se à educação escolar, mas esta a desafia e se contrapõe propondo uma educação física sem práticas repetitivas, ideologizadas no esporte e destituída de criticidade.

Palavras chave: educação física crítica; ensino médio; desmotivação nas aulas

\footnotetext{
${ }^{1}$ Graduanda do Curso de Licenciatura Plena em Educação Física no Centro Superior do Amapá - CEAP.

2 Doutoranda do Programa de Pós-Graduação em Ciências Sociais da UFRN; Mestra em Política, Meio Ambiente e Desenvolvimento Sustentável/UnB; Bacharel em Ciências Sociais pela UNAMA; Professora da Universidade Federal do Amapá - UNIFAP, do Curso de Ciências Sociais.

3 Pos-doutorando em Educação pela UNINOVE; Mestre e Doutor em Educação Física pela Universidade São Judas Tadeu/SP; Licenciado em Educação Física pelo CEAP-AP; Bacharel em Ciências Sociais pela UNIFAP; Pedagogo pelo IESAP-AP. Atualmente professor do Instituto Federal de Educação do Amapá - IFAP.
} 


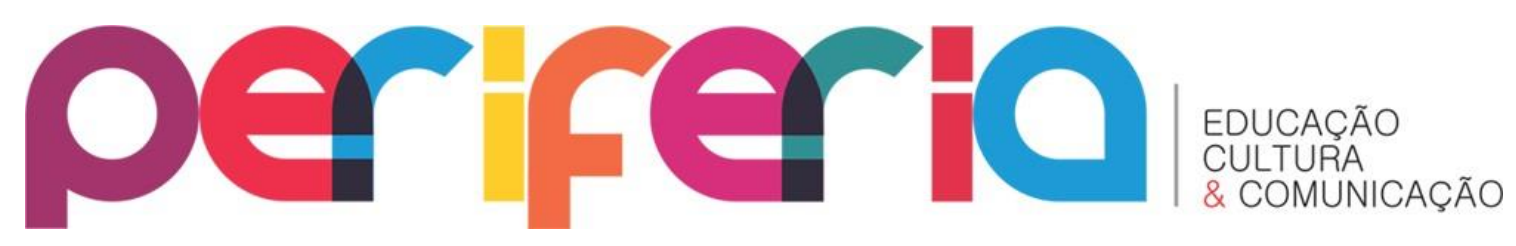

\title{
FOR A CRITICAL PHYSICAL EDUCATION IN MIDDLE SCHOOL IN MACAPÁ
}

\begin{abstract}
This work is based on the results of a research that aimed to answer the reason for the students' lack of motivation in the Physical Education classes in Macapá. The result shows that the problem is based on historical issues and linked to the educational system within a larger context, modern capitalist society with all its systemic apparatus. Historically, Physical Education was based on a Spartan militaristic conception of training imperfect beings, and such legacy influenced the direction of education in this area. Today the institution of sports, via media influence, tries to overlap school education, but it challenges and opposes it by proposing a physical education without repetitive practices, ideologized in sports and devoid of criticism.
\end{abstract}

Keywords: critical physical education; middle school; demotivation in class 


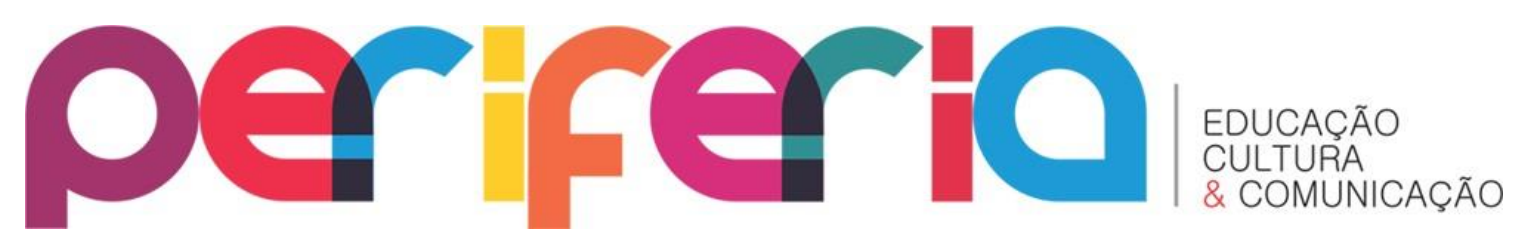

INTRODUÇAO

0 presente estudo tem como intento mostrar em linhas gerais parte das causas da desmotivação nas aulas da disciplina de Educação Física no Ensino Médio. Baseada numa pesquisa, em nível acadêmico, para assentar o Trabalho de Conclusão de Curso do Curso de Educação Física numa instituição de ensino superior na cidade de Macapá/AP, a pesquisa teve como motivação inicial a vivência de uma aluna que apresentou como relato a seguinte questão: enquanto ex-aluna do ensino médio que, dentre todas as disciplinas, sentia que as aulas de educação física eram as que mais the envolviam e apraziam, mas também a incomodava pela atitude de observar a indiferença dos demais colegas de turma nas atividades: enquanto queria mais, os colegas queriam menos ou nem queriam participar.

Entendendo a Educação Física como um rico instrumento educacional e com vasta possibilidade pedagógica de aplicação, a compreensão do fato discorrido não poderia permanecer sem resposta a quem se tornaria tão logo uma profissional da área, uma vez que passou a cursar e estava concluindo o curso superior em Educação Física.

Do trabalho de campo, veio a comprovação do que inicialmente foi uma hipótese: as atividades ministradas eram destituídas de conteúdos relacionais ao cotidiano social, tampouco explicitavam os objetivos e justificativas específicos da atividade e, desse modo, o estímulo ao conhecimento crítico ficava comprometido. Com tal ausência de repertório, vem, obviamente, o desinteresse aos alunos.

A pesquisa que assenta este artigo percorreu os procedimentos metodológicos da pesquisa quantitativa e qualitativa descritiva, fazendo uso tanto da narrativa como de dados estatísticos para a compreensão do fenômeno estudado (CERVO; BERVIAN, 2007). O estudo foi desenvolvido nas escolas de Ensino Médio, do município de Macapá, tendo como público alvo alunos do $3^{\circ}$ ano, uma faixa etária de 16 a 19 anos. Como técnica de coleta de dados, utilizou-se a observação participante, assim, como a entrevista e 


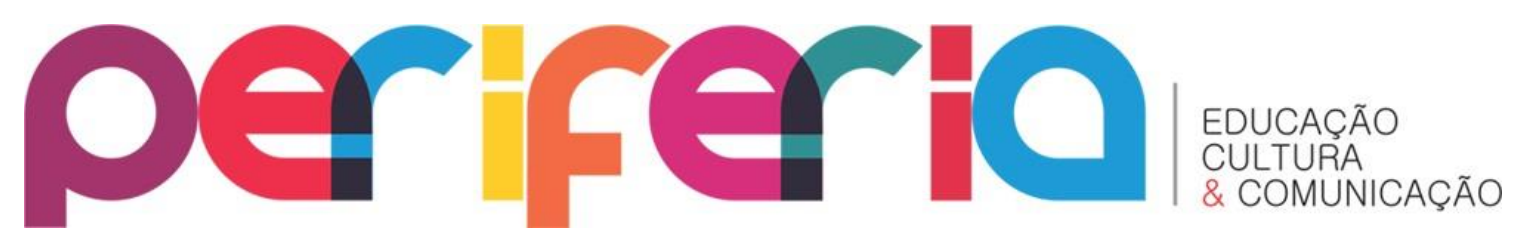

questionário. Segundo Mann (1970), a observação participante é uma "tentativa de colocar o observado do mesmo lado, tornando-se o observador um membro do grupo de molde a vivenciar o que eles vivenciam e trabalhar dentro do sistema de referência deles". Para Goode e Hatt (1969) a entrevista incide em desenvolver com precisão, foco, fidedignidade e legitimidade o ato social como a conversação.

Os dados coletados foram submetidos à análise estatística e analisados a luz da literatura especializada. O que para Cervo e Bervian (2007), faz com que o pesquisador tenha uma compreensão aprofundada dos dados encontrados e uma explicação concisa e convincente. Quanto aos instrumentos, os questionários buscaram abordar temas como: a) preferências pelas disciplinas escolares; b) a importância das disciplinas dentro do currículo escolar; c) a participação dos alunos nas aulas de Educação Física; e, d) a prática da atividade física fora da escola. Dessa forma, procura-se abranger um amplo espectro de questões relacionadas à prática da Educação Física na escola. É importante frisar que, nas respostas obtidas através dos questionários, avaliou-se a representação que os alunos têm a respeito dos seus valores e procedimentos e não propriamente o que eles fazem ou pensam de fato (DARIDO, 2004).

Desse modo, fez sentido sistematizar informações e elaborar um trabalho que serviu e serve de suporte de informação a outros alunos e profissionais da área. Assim como, resgatando algumas ideias principais da pesquisa anterior, nos servem agora como embasamento e suporte de argumento para este presente artigo.

\section{BREVE HISTÓRICO E A LEGISLAÇÃO}

Buscou-se um breve histórico da Educação Física no Brasil, a partir do século $X X$, e as influências e consequências acarretadas até hoje na atual Educação Física - principalmente no Ensino Médio - por medidas tomadas no século passado, estão repercutidas realidade brasileira. 


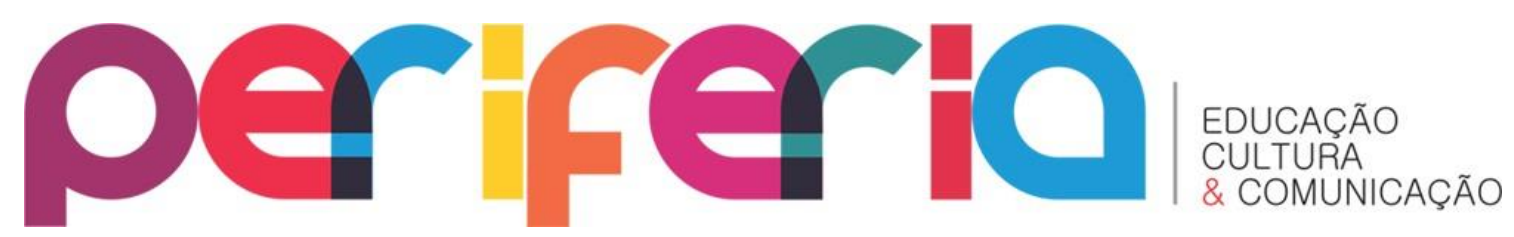

Ao iniciar o século XX, o Brasil deixava de ser Imperial há pouco tempo e caminhava na adaptação da República. Diante dessa reforma estrutural de poder do Estado, a educação brasileira também se reformou perante a nova realidade da sociedade brasileira, principalmente, a Educação Física que, por sua vez, foi formulada e atrelada a um molde feito pela elite dessa passagem histórica, onde era concebida como um projeto de humanidade que, segundo Goellner (2005), era centrado em eliminar as anatomias disformes ao modelo estético e moral escolhido para ser a imagem de uma nação em desenvolvimento.

Seguindo tal pensamento da época, a Educação Física teve sua valorização voltada para adestramento dos seres que eram tidos como perfeitos, seguindo a ideologia militarista espartano - mesmo a tendência da Educação Física do início do século XX, no Brasil, ser higienista e não militarista -, negando os corpos imperfeitos fisicamente (deficientes físicos, mentais, doente, etc.), negando o corpo não branco e o fortalecimento do corpo feminino, sendo este identificado como a 'célula-mater"'4 (GOELLNER, 2005).

Para reafirmar a citação acima, os Parâmetros Curriculares Nacionais (PNCs) do Ensino Fundamental falam sobre o momento da Educação Física no século passado:

Embora a elite imperial estivesse de acordo com os pressupostos higiênicos, eugênicos e físicos, havia uma forte resistência na realização de atividades físicas por conta da associação entre o trabalho físico e o trabalho escravo. Qualquer ocupação que implicasse esforço físico era vista com maus olhos, considerada "menor". Essa atitude dificultava que se tornasse obrigatória a prática de atividades físicas nas escolas (BRASIL, 1997, p. 19).

\footnotetext{
${ }^{4}$ Diversas publicações que orientam a prática de atividade física para as mulheres objetivando o fortalecimento de seu corpo em função da construção de uma maternidade sadia utilizam essa expressão, em especial nos anos 1930 a 1940 (GOELLNER, 2005)
} 


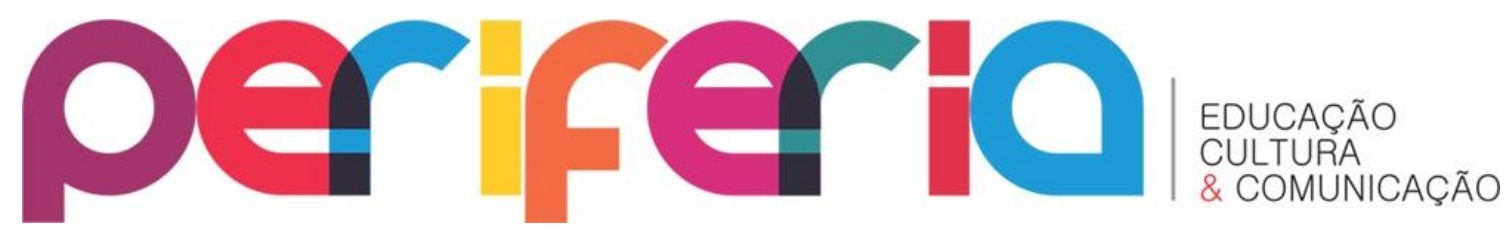

Em continuação à linha de pensamento histórico, já na fala da utilização da Educação Física pelo Estado, segundo os PCN's:

Na década de 70, a Educação Física ganhou, mais uma vez, funções importantes para a manutenção da ordem e do progresso. $O$ governo militar investiu na Educação Física em função de diretrizes pautadas no nacionalismo, na integração nacional (entre os Estados) e na segurança nacional [...] As atividades esportivas também foram consideradas como fatores que poderiam colaborar na melhoria da força de trabalho para o "milagre econômico brasileiro". Nesse período estreitaram-se os vínculos entre esporte e nacionalismo. [...] $\mathrm{Na}$ década de 80 os efeitos desse modelo começaram a ser sentidos e contestados: o Brasil não se tornou uma nação olímpica e a competição esportiva da elite não aumentou o número de praticantes de atividades físicas. Iniciou-se então uma profunda crise de identidade nos pressupostos e no próprio discurso da Educação Física, que originou uma mudança significativa nas políticas educacionais: a Educação Física escolar, que estava voltada principalmente para a escolaridade de quinta a oitava séries do primeiro grau, passou a priorizar o segmento de primeira a quarta e também a pré-escola. 0 enfoque passou a ser o desenvolvimento psicomotor do aluno, tirando da escola a função de promover os esportes de alto rendimento (BRASIL, 1997 p. 21).

No entanto, Bracht (1992) aponta que uma vez que o profissional de Educação Física, ao longo da história, passou por diversas modificações no seu campo de atuação, o mesmo precisa estar preparado para inserção na atualidade. Para o autor, se antes o objetivo primeiro da Educação Física era a preparação para defesa da pátria, para o trabalho na indústria e na agricultura, modernamente o papel do professor de Educação Física é trabalhar a conscientização do aluno de forma coletiva, para que os mesmos possam promover seu bem estar, bem como estar ligado à organização e dinamização de sua vida cotidiana, valorização da cultura local e global, cuidado com sua saúde e consequentemente com a saúde de seu semelhante, e que por meio dos conteúdos trabalhados construam um pensar reflexivo no contexto amplo - o social, para ser preciso - e não simplesmente no contexto 


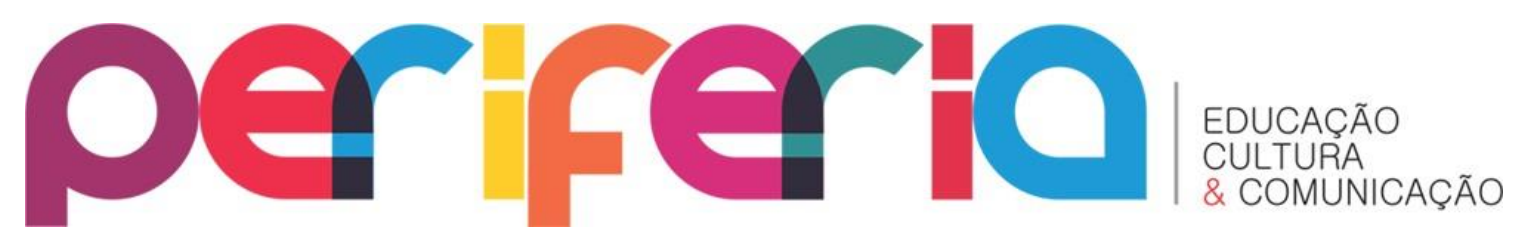

do músculo, uma vez que a Educação Física não interfere na vida das pessoas apenas no formato do físico, mas sim na vida, no contexto global das pessoas.

Na Lei de Diretrizes e Bases da Educação - LDB 9.394, seção I, artigo 26, parágrafo $3^{\circ}$ da LDB, e a partir de outra lei, que é a Lei 10.238, a palavra “obrigatório" é inserida após a expressão “componente curricular”. Assim, o presente artigo de LDB 9.394 consta que:

a Educação Física, integrada à proposta pedagógica da escola, é componente curricular obrigatório na Educação Básica, ajustando-se às faixas etárias e as condições da população escolar, sendo facultativa nos cursos noturnos" (BRASIL, 2001, p. 1 grifo nosso).

O necessário cumprimento das Diretrizes para além do que se inscreve na legislação é o que se espera na luta, na práxis.

\section{UM OLHAR PARA ALÉM DO MURO ESCOLAR: UM OLHAR NO SISTEMA}

É de suma importância que a Educação Física no Ensino Médio não seja uma etapa na vida escolar marcada por repetição dos fundamentos e conteúdos dados ao longo do Ensino Fundamental, mas tem que ser adequado para cada faixa etária como consta da Lei de Diretrizes e Base (LDB). Assim também como não advogamos, evidentemente, o desprezo das práticas dos fundamentos de modalidades esportivas e a execução de gestos técnicos esportivos, no Ensino Médio; porém, crê-se na ressignificação da prática desportiva dentro e integrada com seu contexto cultural.

A proposta das aulas de Educação Física para esses adolescentes deve partir não só da prática de atividades físicas, mas fazer com que os mesmos usem de conhecimentos teóricos, tanto da área de Educação Física quanto do campo relacionado aos problemas sociais, desenvolvendo assim a capacidade de criticidade e debate de seus pontos de vista de forma contextualizada.

Borges e Desbiens (2005, p. 40) defendem que: 


\section{periferio}

A experiência profissional não se resume ao tempo passado a praticar o ensino, se bem que ela o integra. Podemos dizer então que se apoiar na experiência significa que as competências se construiriam graças ao vivido. De fato, a ligação entre a experiência e a formação inicial se estreita claramente, conferindo à [sic] última a missão de dotar docentes iniciantes com atitudes, hábitos e também ferramentas intelectuais para analisar sua(s) prática(s). Podese assim considerar que uma parte do saber dos docentes reside no conhecimento e na utilização apropriada dessas ferramentas.

Betti e Zuliani (2002) apoiavam a ideia que a Educação Física deve assumir a responsabilidade de formar um cidadão capaz de posicionar-se criticamente diante das novas formas da cultura corporal de movimento - o esporte-espetáculo dos meios de comunicação, as atividades de academia, as práticas alternativas, etc.

É destacado nos PCNs que o professor deve ser o responsável pela elaboração de um planejamento dinâmico, que atenda às necessidades e interesses dos alunos, aliando os conteúdos da cultura local às novas tendências da atividade física, sem adotar modismos. Mas os desafios são muitos e a sociedade moderna capitalista com seu aporte teórico neoliberal condiciona a educação aos seus intentos, solapando através do Estado e seu sistema educacional, qualquer intento de uma educação mais libertária. Não há autonomia escolar (nem privada, nem pública) nas decisões sobre o ensino, pois o Estado é uma instituição 'de classes' e não neutro - como a ideologia dominante nos quer fazer crer. Isso possui uma ligação e influência direta no sistema, no ensino e nas disciplinas e não seria diferente com a Educação Física, pois a instituição educacional é resultante da complexificação da sociedade.

Em Vago (1996) encontramos que “A autonomia pressupõe uma determinada inter-dependência, e expressa o grau de liberdade com o qual as relações entre o sistema e o meio ambiente podem, através dos critérios seletivos do sistema, ser por ele próprio reguladas" (LUHMANN, 1970 apud BRACHT, 1992, p. 18). 


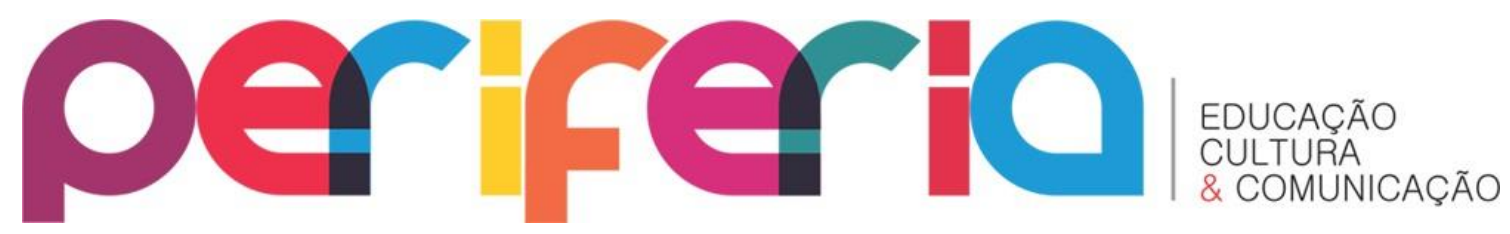

Na Educação Física, a instituição do esporte é que tem se tornado cada vez mais forte na regulação - consequentemente, seletivo - com o advento do uso da mídia e impõem seus códigos dentro da educação escolar induzindo o aluno a enxergar o ensino corporal a partir de seus interesses e como 'verdades absolutas' para essa área. Isso devido à ausência da informação e formação exata durante sua formação escolar no Ensino Fundamental sobre a essência, fundamentos e princípios da Educação Física, levando a perda cada vez maior da autonomia no campo pedagógico, como podemos ver com Duckur (2004), Pereira e Moreira (2005) e Bracht (1992):

É importante citar que o desenvolvimento da instituição esportiva não se dá independente da Educação Física: condicionam-se mutuamente. A esta é colocada a tarefa de fornecer a "base" para o esporte de rendimento. A escola é a base da pirâmide esportiva. É o local onde o talento vai ser descoberto. Esta relação, portanto, não é simétrica (...). $A$ Educação Física assume os códigos de uma outra instituição [a instituição esporte], e de tal forma que temos então não o esporte 'da' escola e sim o esporte 'na' escola, o que indica a sua subordinação aos códigos/sentidos da instituição esportiva. (...) 0 que pode ser observado é a transplantação reflexa destes códigos do esporte para a Educação Física. Utilizando uma linguagem sistêmica, poder-se-ia dizer que a influência do meio ambiente (esporte) não foilé selecionada (filtrada) por um código próprio da Educação Física, o que demonstra sua falta de autonomia na determinação do sentido das ações em seu interior. (BRACHT, 1992, p. 22, grifo nosso).

E Vago (1996), seguindo a linha de raciocínio acima, comenta:

Para a compreensão de que o "esporte da escola" pode "intervir na história cultural da sociedade" [...] É preciso que se afirme radicalmente essa capacidade de intervenção da escola na sociedade, pois o que de pior poderia acontecer à idéia de se construir um esporte como a prática cultural portadora de valores que privilegiam, por exemplo, o coletivo e o lúdico, é o enclausuramento dessa idéia na escola, como se ela fosse possível e desejada somente em seu interior. Aprisionar essa idéia na escola é antecipar a sua morte. É o que pode ocorrer, paradoxalmente, se aceitarmos que 0 


\section{periferio}

esporte "da escola", só possa ser praticado no interior de seus muros. Aceitar isso seria negar a gênese social da escola e a sua permanente inserção na totalidade social, negar que ela possa oferecer à sociedade outras possibilidades de fruição do esporte. Ora em última instância, isso seria esvaziar de sentido o ensino do esporte como um dos temas da Educação Física (VAGO, 1996, p. 12-13)

Portanto, continua Vago (1996, p. 13):

Não se trata, então de agir apenas para que a escola tenha o "seu" esporte. Trata-se de problematizar a prática cultural do esporte da sociedade (que é, ao mesmo tempo, o esporte da e na escola), para reinventá-lo, recriá-lo, reconstruí-lo. [...] Oferecer a sociedade outras possibilidades de prática de esporte. E é isso que a coloca numa posição de produzir novos conhecimentos acerca do esporte, colocando-o à disposição da sociedade.

A crítica reflexiva que nos é possibilitada aqui, à luz dos PCNs que versam sobre um planejamento dinâmico, que atenda às necessidades e interesses dos alunos, aliando os conteúdos da cultura local às novas tendências da atividade física, sem adotar modismos, cremos, somente virá com a autonomia pedagógica do 'fazer autônomo' a partir das significações locais, endógenas ao local e não determinadas pelas determinações midiáticas e externalidades vinculadas a cultura esportiva do adestramento ou do esporte-espetáculo. Significações estas as quais o aluno adolescente se sinta interessado porque pertencente e construtor.

$\mathrm{Na}$ verdade, tudo isso está ligado a uma mudança e, tal mudança, ocorre a partir da construção de uma "cultura escolar de esporte" sem reproduções hegemônicas como alegou Valter Brach (1992) - fato entendido por Vago (1996, p. 4) como um "movimento propositivo de intervenção na história cultural da sociedade", a partir da escola enquanto instituição social formativa. Desse modo, os desafios estão postos para a Educação Física escolar. 


\title{
periferio
}

3. O DESAFIO PARA A MANUTENÇÃO DO INTERESSE, DOS ADOLESCENTES, NAS AULAS DE EDUCAÇÃO FÍSICA

A Educação Física escolar para os adolescentes, além de demandar significado e sentimento de interesse e pertença, tem que ser algo que esteja em constante mudança. Essa percepção está na ideia de conhecimento explicado por Duckur (2004) que, considerando as mudanças psicossociais e fisiológicas próprias dessa idade (que nem, mesmo, os adolescentes entendem), afirma que, para manter os adolescentes interessados, instigados e indagados em relação ao conteúdo que estiver sendo ministrado, é necessário o professor entender que, por exemplo, o esporte só é um dos meios para chegar nesses alunos e não um fim. Além, claro, do discernimento sobre a Educação Física na atualidade que passou 'do saber fazer o movimento' para o 'saber resolver problemas e ter noção de criticidade' sobre qualquer assunto.

Sobre essa utilização do esporte como um meio de ensino para outros fins, Kunz (2001, p. 36-37) relata:

\begin{abstract}
Em lugar de ensinar os esportes na Educação Física Escolar pelo simples desenvolvimento de habilidades e técnicas do esporte, numa concepção crítico-emancipatória, deverão ser incluídos conteúdos de caráter teórico-prático que além de tornar o fenômeno esportivo transparente, permite aos alunos melhor organizar a sua realidade de esporte, movimentos e jogos de acordo com as suas possibilidades e necessidades. Isso implica que no ensino além do trabalho produtivo de treinar as habilidades e técnicas - que nunca deixam de ser importantes - deve ser considerado dois outros aspectos que, em muitas instancias, são mais importantes. Trata-se da interação social que acontece em todo processo coletivo de ensinar e aprender, mas que deve ser tematizada enquanto objetivo educacional que valoriza o trabalho coletivo de forma responsável, cooperativa e participativa.
\end{abstract}

Para ratificar a crítica ao esporte, Celante (2000) diz que se preocupa em demasia ao mostrar a influência do esporte como única pratica 


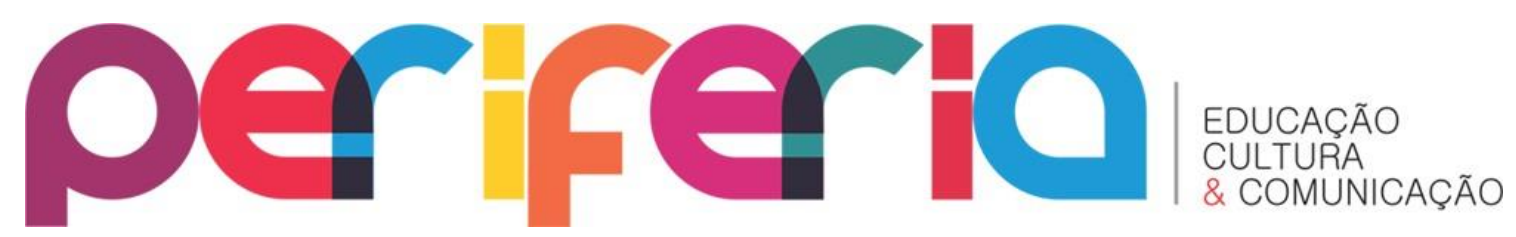

pedagógica. Por assim ser, na concepção critico-superadora, debate-se em foco principal sobre o conhecimento ser tratado de jeito diferenciado, de um jeito que dê a possibilidade de ser expresso na realidade, podendo colocar de frente o que o aluno já sabe do seu dia a dia com o conhecimento científico e, no meio desse momento, levá-los a uma reflexão do conteúdo, respeitando a realidade social e a sociedade na qual está inserido.

Uma preocupação de professores comprometidos com a prática pedagógica e, algumas pesquisas, demonstram fundamentos nas reclamações, feitas por parte dos alunos de Ensino Médio em relação à Educação Física, pois o que é usado como base das aulas são apenas as modalidades esportivas que, além de se tornarem atividades repetitivas e rotineiras durante toda a formação escolar, tornam-se algo desmotivador para grande parte dos alunos que não alcançaram as habilidades, gestos técnicos corretos e padrão de movimentos necessários para as modalidades esportivas. Isso tudo aplicado sem reflexão alguma em cima do que eles estavam vivenciando na parte prática e a parte teórica é mais comprometida ainda - pois inexiste. Isso leva ao abandono das aulas por grande parte dos alunos que não se veem atendido nas suas necessidades.

Em pesquisa desenvolvida em oito escolas, públicas e particulares (BETTI, 1992), verifiquei que o conteúdo desenvolvido raramente ultrapassa a esfera esportiva; mais do que isto, restringe-se ao voleibol, basquetebol e futebol. Fato ainda mais alarmamente foram as respostas dos alunos que, na maioria, afirmaram que gostariam de aprender outros conteúdos (BETTI, 1999, p. 25).

Betti e Zuliani (2002) evidenciam que a Educação Física no Ensino Médio tem o dever de atender às necessidades desses alunos, não somente aprofundar ou apenas reproduzir os conteúdos trabalhados anteriormente no Ensino Fundamental. De acordo com os PCN's:

É fundamental também que se faça uma clara distinção entre os objetivos da Educação Física escolar e os objetivos do 


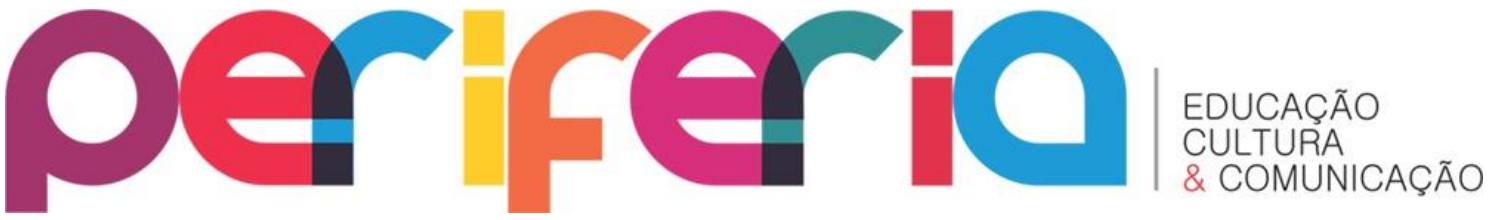

esporte, da dança, da ginástica e da luta profissionais, pois, embora seja uma referência, o profissionalismo não pode ser a meta almejada pela escola. A Educação Física escolar deve dar oportunidades a todos os alunos para que desenvolvam suas potencialidades, de forma democrática e não seletiva, visando seu aprimoramento como seres humanos. Nesse sentido, cabe assinalar que os alunos portadores de deficiências físicas não podem ser privados das aulas de Educação Física (BRASIL, 1997, p. 24).

Isso suporta e reafirma a discussão de Vago (1996) sobre o esporte na/da escola quando diz que não se trata, então de agir apenas para que a escola tenha o "seu" esporte. Trata-se de problematizar a prática cultural do esporte da sociedade (que é, ao mesmo tempo, o esporte da e na escola), para reinventá-lo, recriá-lo, reconstruí-lo.

Para Betti e Zuliani (2002), quando Vago (1996) advoga em defesa da problematização da prática cultural do esporte da sociedade (sendo este esporte 'da escola' e 'na escola') com criticismo e embasado numa prática pedagogia que o reinvente, o recrie e o reconstrua continuamente, entendem que isso se estende a toda prática da cultura corporal do movimento.

\section{CONSIDERAÇÕES FINAIS}

Nesse presente estudo, vemos que é dever do professor utilizar o esporte como um dos meios, e não como um único fim para alcançar a cultura corporal do movimento e se fechar para inúmeras possibilidades e capacidades que podem ser alcançadas nas aulas de Ensino Médio.

Com isso o ensino da Educação Física se apropria no uso do lúdico que tenha como principal foco estimular a criatividade humana, levando em consideração que o conhecimento em si não é algo estável e constante e, sim, que se mantêm sempre em mudança (DUCKUR, 2004). É dever primordial do professor para com os alunos, nas aulas, a atitude de fazê-los encontrar sentido e significado no que fazem e tornar-se alguém que saiba conhecer, fazer, ser e consequentemente, conhecer o outro. 


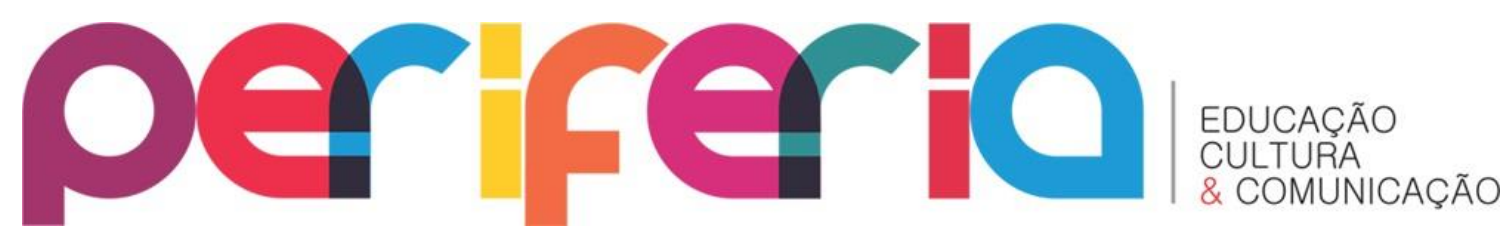

Dentro da realidade atual em processo desde 2016 na sociedade brasileira, tratando-se especificamente da reforma do Ensino Médio, a indagação que sobressai e permanece, como sugestão, deve se tornar um importante tema de pesquisa pode ser extraído da seguinte questão: se num período democratizante das políticas públicas no País a concepção de um ensino crítico da Educação Física ainda não tinha se estabelecido, efetivamente, na totalidade de suas dimensões - embora tenha ocorrido considerado número de ações e esforços por parte dos grupos da categoria que assim o concebem -, como o ensino da Educação Física poderá se tornar crítico, hoje, num retorno às conduções e diretrizes políticas e ideológicas, claramente, de base neoliberal assumidas pela atual gestão do Governo Federal?

Assim sendo, o referido trabalho que teve como objetivo demonstrar, a partir da investigação (pesquisa) a percepção dos alunos do ensino médio e os fatos relacionados à sua desmotivação nas aulas de Educação Física conclui, portanto, que a ausência de interação entre os conteúdos da disciplina com a práxis social da comunidade escolar, somados aos interesses institucionalizados da cultura do esporte, limita a possibilidade pedagógica de instruir o aluno sob uma visão crítica, tanto sobre o ponto de vista pessoal quanto profissional. E, no atual momento do País, a Reforma do Ensino Médio seria um instrumento a dar conta de viabilizar o referido conteúdo de promoção a uma educação crítica, mas não o percebemos comprometido com tal ideário.

\section{REFERÊNCIAS}

BETTI, I. C. Rangel. Esporte na escola: mas é só isso, professor? Motriz - v.1, n.1, p. 25-31, junho/1999. Disponível em:

<http://www.rc.unesp.br/ib/efisica/motriz/01n1/4_Irene_form.pdf>. Acesso em: 15 ago. 2016. 


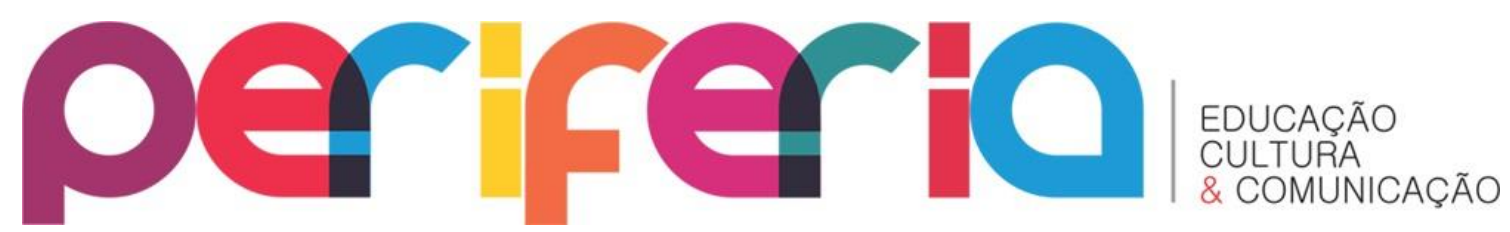

BETTI, M.; ZULIANI, L. R. Educação Física Escolar: Uma proposta de diretrizes pedagógicas. Revista Mackenzie de Educação Física e Esporte. São Paulo: Editora Mackenzie, n.1, Ano.1, p.73-81, 2002.

BORGES, C; DESBIENS, J. F. A formação dos docentes de educação física. In: BORGES, C; DESBIENS, J. F. (Orgs.). Saber, formar e intervir para uma educação física em mudança. Campinas: Autores Associados, 2005.

BRACHT, V. Aprendizagem social e Educação Física. Porto Alegre: Magister, 1992.

BRASIL. Lei $n^{\circ}$ 9.394, de 20 de Dezembro de 1996. Estabelece as Diretrizes e Bases da Educação Nacional. Diário Oficial [da] República Federativa do Brasil, Poder Executivo, Brasília, DF, 23 de Dez. 1996. Seção I, p. 2783327841.

Lei $\mathrm{n}^{\circ} 10.328$, de 12 de Dezembro de 2001. Introduz a palavra obrigatório após a expressão curricular, constante no parágrafo $3^{\circ}$ do artigo 26 da Lei n 9.394, de 20 de Dezembro de 1996, que estabelece Diretrizes e Bases da Educação Nacional. Diário Oficial [da] República Federativa do Brasil, Poder Executivo, Brasília, DF, 12 de Dez. 2001, Seção I, p. 1.

Secretaria de Educação Fundamental. Parâmetros curriculares nacionais: Educação física / Secretaria de Educação Fundamental. Brasília, MEC/SEF, 1997.

- Ministério da Educação e do Desporto. Secretária de Ensino Médio. Parâmetros Curriculares Nacionais do Ensino Médio: área linguagens e códigos, 1999.

CELANTE, A. R. Educação Física e cultura corporal: uma experiência de intervenção pedagógica no Ensino Médio. 2000. 174f. Dissertação: Mestrado em Educação Física. Faculdade de Educação Física, Universidade Estadual de Campinas, Campinas, SP, 2000.

CERVO, A. L.; BERVIAN, P. A. Metodologia Cientifica. $6^{\circ}$ Ed. São Paulo: Pearson Prentice Hall, 2007.

DARIDO, S. C. A educação física na escola e o processo de formação dos não praticantes de atividade física. Revista Brasileira de Educação Física Especializada, São Paulo, v.18, n.1, p.61-80, jan./mar. 2004.

DUCKUR, L. C. B. Em busca da formação de indivíduos autônomos nas aulas de Educação Física. Campinas, SP: Autores Associados, 2004. - (Coleção Educação Física e Esportes). 


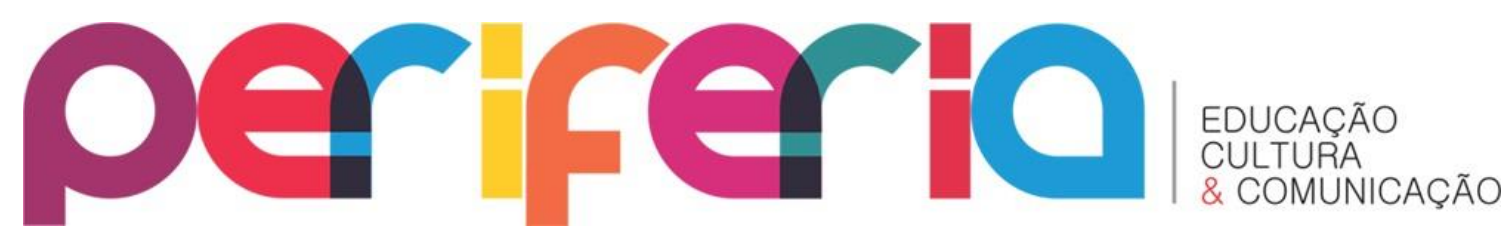

GOELLNER, S. V. Da criança de hoje depende o Brasil de amanhã: raça e Gênero na educação física brasileira no início do século XX. In: MIGUEL, Maria Elizabeth B.; CORREA, Rosa L. T. (Org.). A Educação Escolar em perspectiva histórica. Campinas: Autores Associados, 2005.

GOODE, W. J.; HATT, P. K. Métodos em pesquisa social. 3 Ed. São Paulo: Nacional, 1969. Capítulos 2 e 3.

KUNZ, E. Transformação didático-pedagógica do Esporte. Ijuí, RS: Unijuí, 1994.

MANN, P. H. Métodos de investigação sociológica. Rio de Janeiro: Zahar, 1970. Capítulos 4, 5, 6, 7 e 8.

PEREIRA, R. S.; MOREIRA, E. C. A participação dos alunos do Ensino Médio em aulas de Educação Física: Algumas considerações. Revista da Educação Física/UEM. Maringá, v. 16, n. 2, p. 121-127, 2. Sem. 2005.

VAGO, T. M. O “esporte na escola” e o "esporte da escola": da negação radical para uma relação de tensão permanente: um diálogo com Valter Bracht. Movimento. Rio Grande do Sul, Ano III - N ${ }^{\circ} 5$ - 1996/2. Disponível em: <http://seer.ufrgs.br/Movimento/article/viewFile/2228/936>. Acesso em 15 ago. 2016. 